\title{
PHYSIOLOGICAL DISTURBANCES DURING EXPERIMENTAL DIPHTHERITIC INTOXICATION. II. HEPATIC GLYCO- GENESIS AND GLYCOGEN CONCENTRATION OF CARDIAC AND SKELETAL MUSCLE ${ }^{1}$
}

\author{
BY HERMAN YANNET AND DANIEL C. DARROW \\ (From the Department of Pediatrics, Yale University School of Medicine, \\ New Haven)
}

(Received for publication May 20, 1933)

In the first paper of this series (12) it was pointed out that during diphtheritic intoxication in rabbits there was evidence of liver disturbance, manifested by a marked rise in the amino-acid nitrogen which in the more severe intoxications was accompanied by a hypoglycemia. When smaller doses of toxin were injected the amino-acid nitrogen changed but little, while the blood sugar remained relatively normal or rose to hyperglycemic levels. Accompanying these changes the nonprotein nitrogen rose independently of the amino-acid nitrogen, a finding which seemed to be associated with the nephritis which could be demonstrated histologically.

In order to associate, if possible, these findings of hypoglycemia, hyperglycemia and normal sugar values with liver injury, the assumption was made that the two chief functions of the liver concerned with carbohydrate metabolism may be injured separately or in varying degrees. It was felt that the failure of deaminization as indicated by the elevated amino-acid nitrogen concentrations could be interpreted as a type of injury that might be associated with the failure of hepatic glyconeogenesis leading to hypoglycemia. However, if the formation of glucose from non-carbohydrate material is only slightly impaired, a failure of hepatic glycogenesis would result in hyperglycemia.

The following experiments were designed to study the ability of rabbits suffering from diphtheritic intoxication to store glycogen in the various tissues. The effect of intravenous injections of glucose, with and without insulin, on the liver and heart glycogen concentrations, is reported.

\section{PROCEDURE AND METHODS}

Rabbits weighing about 1500 grams were injected intravenously with $3 / 4$ to 1 minimal lethal dose of diphtheritic toxin. This dose caused death in from 3 to 7 days. The rabbits were on a stock diet consisting of oats and greens until 24 hours before the injection of the toxin, when the food was removed

1 This work was aided by a grant from The Corn Products Refining Company. 
from the cages. Starvation was maintained throughout the balance of the experiment; water was offered freely. The level of the blood nonprotein nitrogen was used as a fairly reliable index of the severity of the intoxication; this was determined daily and when it reached 100 to $150 \mathrm{mgm}$. per cent or higher the operative phase of the experiment was started. (Previous experience indicated that diphtheritic rabbits with a blood nonprotein nitrogen level of this magnitude die within 24 to 48 hours.) As an anesthetic, one-half cubic centimeter of a 10 per cent freshly prepared amytal solution per kilogram of body weight was injected intraperitoneally. Following the development of adequate anesthesia the liver was exposed by a mid-line upper abdominal incision. A section of liver weighing approximately 3 to 5 grams was removed, bleeding being effectively controlled by a ligature, and was immediately cut into small pieces and dropped into a weighed tube containing 60 per cent potassium hydroxide for glycogen determination. In one series of animals $5 \mathrm{cc}$. of a 50 per cent glucose solution was then injected intravenously immediately, and again after an interval of 20 minutes. In another series the same technique was employed except that $21 / 2$ units of insulin were injected along with the glucose solution. One hour following the last administration of glucose another section of liver was obtained for glycogen determination. (Preliminary experiments had shown that the increase of liver glycogen was approximately the same after one as it was after two hours.) The hearts were removed at the same time as the second liver section. The controls were subjected to precisely the same procedure, including the starvation régime, for a similar period of time.

Data referable to the glycogen content of liver, heart and skeletal muscle were obtained from another series of animals on a similar fasting régime. The tissues were removed within 30 seconds after the animal was stunned by a blow at the base of the skull. At the time of these determinations the blood nonprotein nitrogen of the diphtheritic animals was about 150 to $200 \mathrm{mgm}$. per cent. The same dose of toxin was used in this series as in the one previously described.

The glycogen method employed was fashioned after Pflüger's original procedure but was sufficiently modified to warrant description. About 5 grams of tissue were cut into small sections as soon as possible after removal from the animal and collected in a weighed centrifuge tube of $100 \mathrm{cc}$. capacity containing $10 \mathrm{cc}$. of 60 per cent potassium hydroxide solution, which was then reweighed. Digestion was allowed to take place in a steam bath for a period of three hours, or until a relatively clear liquid resulted. Approximately 75 to $80 \mathrm{cc}$. of 95 per cent alcohol were then added and the tube allowed to remain in a refrigerator overnight to insure complete glycogen precipitation. The tube was then centrifuged at moderate speed for 10 minutes, the supernatant fluid siphoned off and the glycogen precipitate washed with 25 cc. of 95 per cent alcohol. Following another centrifugation for 10 minutes the supernatant fluid was again removed. One drop of phenolphthalein and $25 \mathrm{cc}$. of water were added and the resulting solution neutralized by the careful addition of 25 per cent hydrochloric acid. (This usually required 4 to 5 drops.) Two and one-half cc. of the acid were then added, producing a final acidity approximately equivalent to a $21 / 2$ per cent hydrochloric acid solution. The glycogen was then hydrolyzed by heating in a steam bath for three hours. The resulting solution was neutralized and made up to a suitable volume and the glucose content determined in aliquots by Somogyi's modification of the Shaffer-Hartmann sugar method. The glycogen content is expressed as milligrams of glucose per gram of tissue. The method has an error in duplicates of about 8 per cent. 


\section{RESULTS}

In Chart 1 are graphically tabulated the results of the determinations of the glycogen content of liver, muscle and heart, in both diphtheritic and normal animals. There are two striking observations to be made: first, that there is essentially no difference in the glycogen content of the heart and skeletal muscles of the diphtheritic as compared to the normal animals; second, that there is a definite diminution in the glycogen content of diphtheritic livers as compared to normals.

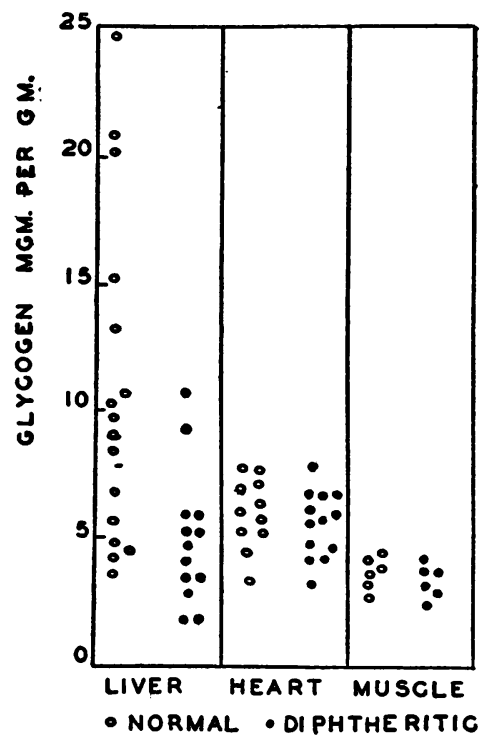

Chart 1. The Glycogen Concentration of Liver, Heart and Muscle in Normal and Diphtheritic Rabbits

The glycogen content of normal and diphtheritic livers before and after the injection of glucose and glucose plus insulin is graphically represented in Chart 2. The glycogen concentration of the liver before and after the glucose and glucose plus insulin injections is represented by a circle and arrow-end respectively. The length of the intervening line represents the actual increase in glycogen concentration in milligrams per gram of tissue. In the normal animals the injection of glucose brought about an increase in the glycogen content of the liver which varied from 6 to $29 \mathrm{mgm}$. per gram of tissue, in other words an increase of from approximately 0.5 to 2 per cent in glycogen concentration. The addition of insulin, it will be seen, had no appreciable effect in normal animals, a finding which is similar to that described by other investigators.

In the diphtheritic animals, on the other hand, following the injection of glucose, the increase in liver glycogen varied from less than $1 \mathrm{mgm}$. to 


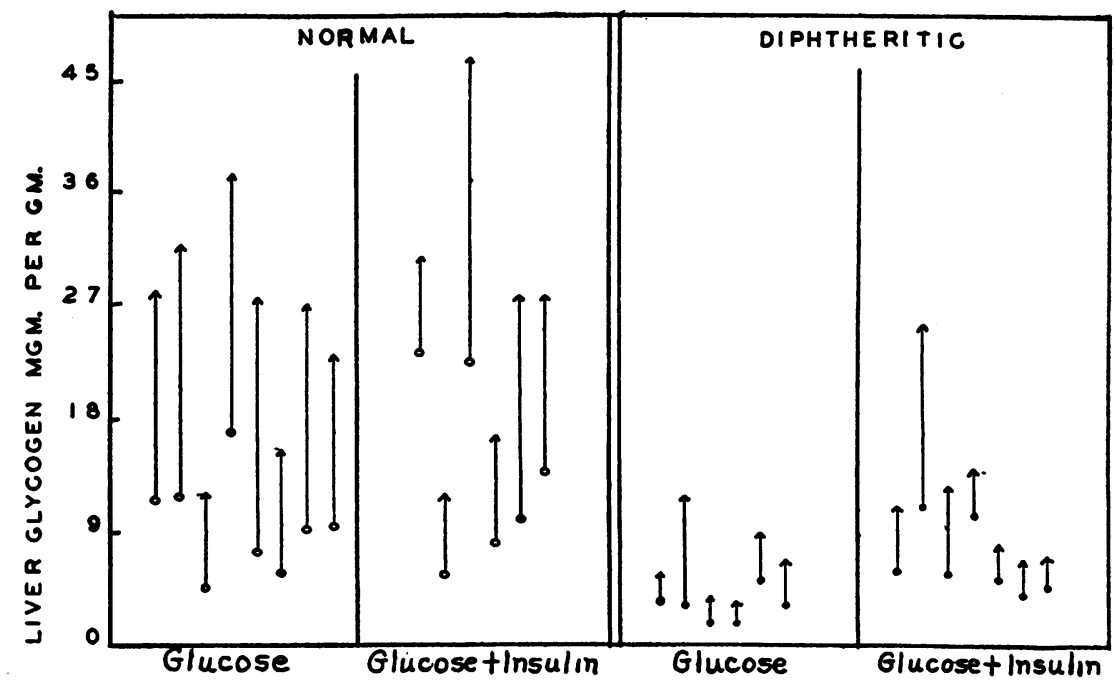

Chart 2. The Change in Glycogen Concentration of the Liver of Normal and Diphtheritic Rabbits Following the Injection of Glucose and Glucose Plus Insulin.

The lower ends of the arrows indicate initial concentrations and the arrow heads final concentrations.

$6 \mathrm{mgm}$. per gram of tissue, an increase of from 0.1 to 0.6 per cent. In other words, it was possible to demonstrate a marked decrease in the glycogenetic ability of the livers in diphtheritic animals. It should also be noted that the addition of adequate doses of insulin ( 1 unit per gram of glucose injected) had no effect in augmenting hepatic glycogenesis in the diphtheritic animals.

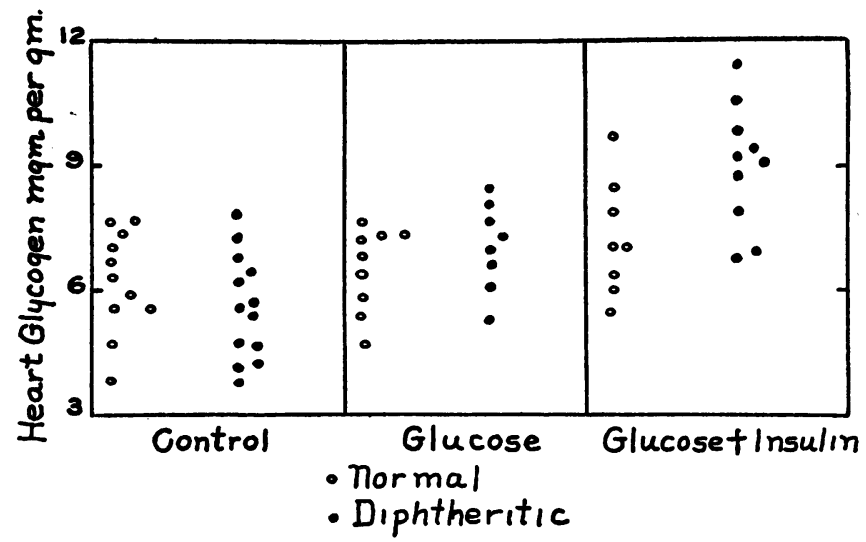

Chart 3. The Glycogen Concentration in Normal and Diphtheritic Hearts of Rabbits Untreated and Following the Injection of Glucose and Glucose Plus Insulin. 
In Chart 3 the results of the glycogen determinations on the hearts of the normal and diphtheritic animals, following the intravenous injection of glucose, with and without insulin, are represented. These have been compared to the values found in the untreated animals. There is no significant difference in the cardiac glycogen of normal and diphtheritic animals following injections of glucose. However, the cardiac glycogen of diphtheritic animals following the injection of glucose plus insulin may be significantly greater than in the other groups.

\section{DISCUSSION}

Early in this investigation it was appreciated that diphtheritic rabbits refuse all food relatively soon after receiving an injection of toxin and should, therefore, be regarded as fasting animals. Since one of the striking effects of starvation is a depletion of the glycogen stores, it was apparent that in a comparative study of glycogen content of various tissues in normal and intoxicated animals, one would have to consider not only the effect of the diphtheria toxin but also of starvation. It was felt that the most practical procedure for minimizing this difficulty was to maintain both groups of animals on a similar fasting régime. We thus felt that any differences encountered in the glycogen concentrations of the examined tissues could, with greater reliability, be attributed to the effect of the diphtheria toxin alone.

Although diphtheria, both clinically and experimentally, is a generalized disease process and not limited to any one particular organ, it is nevertheless true that the myocardial involvement is an outstanding and relatively frequent manifestation of a severe intoxication. Warthin (1) in his review of the anatomical changes in the heart in diphtheria suggested the possibility that some of the encountered lesions may well be related to a nutritional disturbance. Schwentker and Noel (2), who, on the basis of their experimental and clinical investigations and a review of the literature, stressed the theory of insulin dysfunction as the cause of the carbohydrate disturbance, believed that failure of glycogenesis played an important rôle in the myocardial insufficiency. It was, therefore, with interest that we noted no essential difference in the glycogen concentration of the hearts of diphtheritic and normal animals. As far as we can determine from a review of the available literature there have been no determinations of heart glycogen in diphtheritic animals.

The few determinations of heart glycogen before and after injection of glucose cannot be interpreted with certainty. There is no evidence that the amount of glucose injected increased the heart glycogen in either the diphtheritic or normal animals. The group of diphtheritic animals subjected to intravenous injection of glucose plus insulin have slightly higher heart glycogens than the controls. The difference in the averages is just three times the probable error of the differences. However, in a small 
number of determinations such a difference cannot be regarded as more than suggestive.

An occasional reference to muscle glycogen determinations in experimental diphtheritic intoxication is found in the literature. Schwentker and Noel found the muscles of three animals completely devoid of glycogen and in a fourth, 0.16 per cent. Rosenthal (3) in three rabbits found the muscle glycogen to be $0.165,0.245$ and 0.305 per cent respectively. We have found in six animals the glycogen concentration to vary from 0.23 to 0.43 per cent, but we have also found that in six normal animals under a similar starvation régime the muscle glycogen was approximately of similar magnitude, varying from 0.26 to 0.42 per cent. In other words, as in the case of cardiac glycogen, no essential difference could be demonstrated between the muscle glycogen of normal and diphtheritic animals.

An entirely different picture is presented when one examines the values for the glycogen concentration of the livers in the diphtheritic animals. In this case there is a definite decrease in the intoxicated rabbits, the glycogen content varying from 0.12 to 0.63 per cent, and averaging about 0.35 per cent, while in the normal but fasted rabbits the concentration in the liver varies from 0.4 to 2.0 , averaging about 1.0 per cent. Whether the liver shares to a greater extent in the general systemic intoxication than does either the heart or muscle, as these data would seem to imply, is not absolutely clear. Histologically the liver exhibits more injury than the cardiac or skeletal muscle. However, it is probable that a large part of the liver glycogen serves primarily as storage material, and that it is the diminution in this fraction which accounts for the marked difference in the glycogen concentration encountered. On the other hand in the heart and to a lesser extent in muscle, most of the glycogen content is intimately related to the immediate metabolic needs of the tissues in question, and is, therefore, less likely to be involved in an injury of relatively similar degree than is the glycogen of the liver.

The data obtained in the study of hepatic glycogenesis show a marked disturbance in the ability of the diphtheritic liver either to store or to form glycogen or both. Furthermore, the injection of insulin does not correct this deficiency. Numerous investigators have demonstrated a marked decrease in carbohydrate tolerance as evidenced by diabetic-like sugar tolerance curves. Moreover, Lawrence and Buckley (4), Netzley (5) and Sweeney (6) in animals, and Elkeles and Heimann (7) and Schwentker and Noel (2) in human cases of diphtheria, have found a decided impairment in the normal depressing action of insulin on the sugar tolerance curves. As was previously pointed out, this has been interpreted by some to signify insulin dysfunction or actual insufficiency. It is apparent that an inability of the liver to remove glucose for storage as glycogen would adequately explain a delayed or elevated sugar tolerance curve and apparent refractoriness to insulin. Obviously, such a failure of hepatic glycogenesis 
does not necessarily signify any inability to burn carbohydrate. In the third paper of this series we demonstrate by means of respiratory quotients determined during the course of the intoxication that diphtheritic rabbits can burn carbohydrate.

The occurrence of severe liver injury during diphtheritic intoxication is by no means unrecognized. Pathologically this was noted many years ago by Babes (8), Welch and Flexner (9), Fahr (10), and others. Histologically, the lesion consists essentially of varying degrees of necrosis in the region of the central vein. From our own experience in examining numerous sections of liver obtained from diphtheritic animals, this has been the most constant and striking pathological finding. In many cases the destruction was so extensive that very little normal hepatic tissue could be seen.

It may be pertinent, in this connection, to point out the striking similarity which exists, as far as evidence of disturbance in carbohydrate metabolism is concerned, between diphtheritic intoxication and other conditions in which liver injury is the principal pathological finding, namely, phosphorus, chloroform and hydrazine poisoning and yellow fever. In these conditions there have been demonstrated hypoglycemia, diabetic-like sugar tolerance curves, marked reduction in liver glycogen, and increases in blood amino-acid nitrogen (11).

\section{SUMMARY}

1. The liver glycogen of fasted rabbits injected intravenously with diphtheria toxin is definitely diminished in comparison with that of controls subjected to similar periods of fasting. Under these conditions, no significant difference was noted in the concentration of glycogen in heart and muscle of diphtheritic and control rabbits.

2. A marked diminution in hepatic glycogenesis following the intravenous injection of glucose was noted in diphtheritic rabbits. The injection of insulin along with the glucose did not alter hepatic glycogenesis.

3. The concentrations of heart glycogen of normal and diphtheritic rabbits following the injection of glucose, with and without insulin, showed no significant differences.

4. It is pointed out that the destruction of liver parenchyma, demonstrated anatomically in diphtheritic intoxication, is accompanied by a failure of hepatic glycogenesis which is responsible for some of the disturbances in carbohydrate metabolism described in this condition.

\section{BIBLIOGRAPHY}

1. Warthin, A. S., J. Infect. Dis., 1924, xxxv, 32. The Myocardial Lesions of Diphtheria.

2. Schwentker, F. F., and Noel, W. W., Bull. Johns Hopkins Hosp., 1930, xlvi, 259. The Circulatory Failure of Diphtheria. II. The Carbohydrate Metabolism in Diphtheria Intoxication. 
Ibid., 1930, xlvi, 359. The Circulatory Failure of Diphtheria. III. The Treatment of the Circulatory Failure of Diphtheria.

3. Rosenthal, F., Arch. f. exper. Path. u. Pharmakol., 1914, 1xxv, 99. Utber die Störungen des Kohlenhydratstoffwechsels bei der experimentellen Diphtherievergiftung.

4. Lawrence, R. D., and Buckley, O. B., Brit. J. Exper. Path., 1927, viii, 58. The Inhibition of Insulin Action by Toxemias and its Explanation. I. The Effect of Diphtheria Toxin on Blood Sugar and Insulin Action in Rabbits.

5. Netzley, R. E., Am. J. Dis. Child., 1929, xxxvii, 511. The Effect of Diphtheria Toxin on the Action of Insulin; a Study of the Effect of Infections on Carbohydrate Metabolism in Diabetes Mellitus.

6. Sweeney, J. S., Arch. Int. Med., 1928, xli, 420. Effect of Toxemia on Tolerance for Dextrose and on the Action of Insulin.

7. Elkeles, A., and Heimann, F., Deutsches Arch. f. klin. Med., 1927, clv, 263. Uber Störungen im Kohlenhydratstoffwechsel bei diphtherie.

Ibid., 1928, clviii, 238 . Weitere Untersuchungen über Störungen im Kohlenhydratstoffwechsel bei Diphtherie.

8. Babes, V., Virchows Arch. f. path. Anat., 1890, cix, 460. Untersuchungen über den Diphtheriebacillus und die experimentelle Diphtherie.

9. Welch, W. H., and Flexner, S., Bull. Johns Hopkins Hosp., 1891, ii, 107. The Histological Changes in Experimental Diphtheria.

10. Fahr, T., Virchows Arch. f. path. Anat., 1916, ccxxi, 38. Beiträge zur Diphtherie-Frage.

11. A. Bodansky, M., J. Biol. Chem., 1923, lviii, 515. The Effect of Chloroform and Phosphorous Poisoning on Carbohydrate Tolerance.

B. Ibid., Am. J. Physiol., 1923, lxvi, 375. The Production of Hypoglycemia in Experimental Derangements of the Liver.

C. Hendrix, B. M., and McAmis, A. J., J. Biol. Chem., 1924, 1xi, 45. Alkalosis Produced by Injections of Hydrazine Sulfate in Dogs.

D. Lewis, H. B., and Izume, S., J. Biol. Chem., 1926, 1xxi, 33. The Influence of Hydrazine and its Derivatives on Metabolism. II. Changes in the Non-protein Nitrogenous Constituents of the Blood and in the Metabolism of Injected Glycine in Hydrazine Intoxication.

E. Ibid., 1926, 1xxi, 51. III. The Mechanism of Hydrazine Hypoglycemia.

F. Williamson, C. S., and Mann, F. C., Am. J. Physiol., 1923, 1xv, 267. Studies on the Physiology of the Liver. V. The Hepatic Factor in Chloroform and Phosphorous Poisoning.

G. Underhill, F. P., and Hogan, A. G., J. Biol. Chem., 1914, xx, 203. Studies in Carbohydrate Metabolism. VIII. The Influence of Hydrazine on the Utilization of Dextrose.

H. Wakeman, A. M., and Morrell, C. A., Arch. Int. Med., 1931, xlvii, 104. Chemistry and Metabolism in Experimental Yellow Fever in Macacus Rhesus Monkeys. III. Blood Sugar and Liver Glycogen.

I. Ibid., 1931, xlviii, 301. Chemistry and Metabolism in Experimental Yellow Fever in Macacus Rhesus Monkeys. IV. Tolerance Tests for Dextrose.

J. Ibid., 1932, xlix, 826. Chemistry and Metabolism in Experimental Yellow Fever in Macacus Rhesus Monkeys. V. Acid-base and Electrolyte Equilibrium.

12. Yannet, H., and Darrow, D. C., J. Clin. Invest., 1933, xii, 767. Physiological Disturbances during Experimental Diphtheritic Intoxication. I. Blood Sugar, Lactic Acid and Nonprotein and Amino-acid Nitrogen. 